\title{
QUALITY OF LIFE OF WEEKLY, DOSE-DENSE VERSUS STANDARD CHEMOTHERAPY FOR OVARIAN CANCER IN THE ICON8 STUDY
}

SP Blagden, A Cook, C Poole, L Howells, I McNeish, A Dean, D Gallardo, J Weon-Kim, D O'Donnell, J Hook, L James, T Perren, Lord R, Dark G, Earl H, Hall M, R Kaplan, J Ledermann, A Clamp

text limited to 250 words

OBJ ECTI VES: To explore the impact of dose-dense chemotherapy on quality of life (QoL) in women with newly-diagnosed ovarian cancer.

METHODS: ICON8 is a randomised phase III trial of standard vs. weekly dose-dense chemotherapy in newly-diagnosed ovarian cancer. Patients were randomised 1:1:1 to 3-weekly carboplatin AUC5/ paclitaxel $175 \mathrm{mg} / \mathrm{m}^{2}$ (Arm 1), 3-weekly carboplatin AUC5 and weekly paclitaxel $80 \mathrm{mg} / \mathrm{m}^{2}$ (Arm 2) or weekly carboplatin AUC2 and weekly paclitaxel $80 \mathrm{mg} / \mathrm{m}^{2}$ (Arm 3). Primary analysis of progression-free survival showed no significant difference between trial arms. All participants took part in the QoL substudy, completing EORTC-QLQ-C30 and OV28 questionnaires at enrolment, before each chemotherapy cycle, then 6-weekly to 9 months. Primary QoL endpoint was global QoL at 9 months, secondary endpoints included social and emotional function, fatigue and neuropathy symptom scores. Statistical significance was assessed by analysis of covariance adjusted for baseline score.

RESULTS: 17,515 QoL questionnaires were completed by 1540 participants. No significant difference between randomised groups was observed in global QoL at 9 months $(p=0.08)$. There was also no difference in emotional function $(p=0.21)$, social function $(p=0.83)$ or fatigue $(p=0.42)$. However, a significant difference was observed in peripheral neuropathy $(p \varangle 0.001)$, with higher mean scores at 9 months in both weekly Arms (27.4, 34.2, 31.3 in arms 1,2,3 respectively). Exploratory analysis indicated that this difference continued to 18 months from randomisation.

CONCLUSIONS:Self-reported 9-month global QoL did not differ significantly between treatment arms. Emotional and social function, and fatigue were also similar. However, significantly worse long-term neuropathy was reported by both weekly treatment groups. These results do not support weekly, dose dense treatment in the upfront management of high risk ovarian cancer. 